\title{
Evaluation Plan for an Airport Surface-Operation Automation Concept
}

\author{
Victor H. L. Cheng \\ Andrew Yeh \\ Optimal Synthesis Inc. \\ Los Altos, California
}

\author{
David C. Foyle \\ NASA Ames Research Center \\ Moffett Field, California
}

Cheng, V.L, Yeh, A. and Foyle, D.C. (2003). Evaluation plan for an airport surface-operation automation concept. Proceedings of the AIAA's 3rd Aviation Technology, Integration, and Operations (ATIO) Technical Forum, Paper AIAA 2003-6796. 


\section{Evaluation Plan for an}

\section{Airport Surface-Operation Automation Concept}

\author{
Victor H. L. Cheng* and Andrew Yeh† \\ Optimal Synthesis Inc. \\ Palo Alto, California
}

\begin{abstract}
The predicted growth in air travel demands capacity enhancement in the National Airspace System, and congestion at key airports has been recognized as one of the most prominent problem areas. With flights operating at limits dictated by operational requirements associated with current airport configurations, airport expansion plans involving addition of new runways and taxiways are being realized to increase the airports' capacities. However, the expansion plans necessarily increase the complexity of the airport configurations, which tends to penalize the efficiency of the system, partially offsetting the capacity-related benefits of the investments. The Surface Operation Automation Research (SOAR) concept has been proposed as a collaborative concept to provide automation for surface-traffic management and the flight deck to enhance the operational efficiency in complex airport environments, thus reversing the penalties to fully realize the capacity benefits sought by the airport expansion plans. Development and evaluation of the SOAR concept is being pursued in a 5-year program, and this paper describes the experiments being designed for an initial evaluation during the second year of this program.
\end{abstract}

\section{INTRODUCTION}

In the National Airspace System (NAS) Operational Evolution Plan (OEP) [1], the FAA recognizes the capacity problem, and specifically identifies congestion at key airports as one of the domains where the problem is most prominent. In any domain of the NAS, traffic capacity can be viewed as a product of two primary factors: usable space and permissible traffic density, i.e., Capacity $=$ Space $\times$ Density . In view of landing and departure rate limits imposed by separation

\footnotetext{
* AIAA Associate Fellow; Principal Scientist.

${ }^{\dagger}$ Software Engineer.

* Research Psychologist.
}

\author{
David C. Foyle \\ NASA Ames Research Center \\ Moffett Field, California
}

requirements, construction of new runways is ultimately inevitable to achieve capacity gain. In addition to the cost of construction, the increase in surface traffic complexity resulting from the airport expansion will incur other indirect costs or penalties that should be taken into consideration.

Figure 1 summarizes the relationships of the two primary factors contributing to available capacity: usable space and permissible traffic density. Increasing usable space through addition of new runways and associated taxiways inherently increases the complexity of the airport layout. The increased airport complexity implies that there are more taxiway intersections and runway crossings to worry about. Any increase in the throughput of the outer runways will lead to a further increase in the need for crossing the inner runways. A similar increase in the throughput of the inner runways reduces the opportunity or time margins for runway crossings to take place. Figure 1 suggests that the increase in airport complexity, increase in traffic rate and decrease in time resources available to air traffic control (ATC) per flight altogether complicate the ATC operation and increase the controllers' decision complexity. The increased ATC complexity would counter the improvement envisioned from the increased usable space and reduced separation. It may be possible to minimize the penalty on arrival and departure rates with procedures to limit runway interruptions by the taxiing traffic, but such changes may lead to an increase in other costs such as taxi delay, workload, safety, etc.

In addition to capacity and efficiency issues, serious surface-traffic safety issues also exist in today's environment. One such issue is the runway incursion problem. The FAA Runway Incursion Reduction Program (RIRP) [2] studies technologies that can provide improved surveillance information to enhance situation awareness of air traffic control (ATC) and the flight crew [3-6].

Automation tools will play an important role in alleviating some of these issues. Recent automation tool development efforts for enhancing surface operation include the Surface Movement Advisor (SMA) [7] and the Surface Management System (SMS) 
$[8,9]$ to facilitate information sharing among various stakeholders. The Surface Operation Automation Research (SOAR) $[10,11]$ project is involved with the development of collaborative automation tools between surface traffic management (STM) and the flight deck to help deliver efficient traffic flow on the surface under complex situations. The SOAR project targets air traffic in the 2020 time frame, counting on advanced communication, navigation, and surveillance (CNS) as enabling technologies.

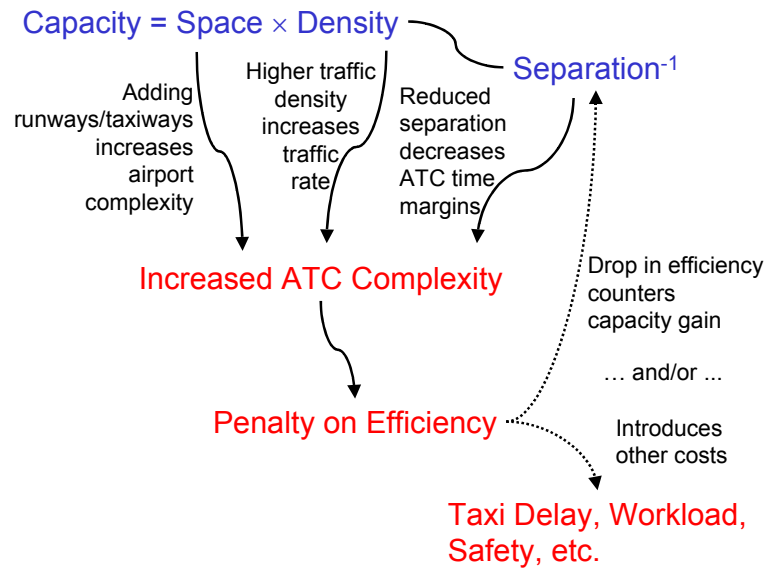

Figure 1. Consequences of Capacity-Enhancement Efforts

To establish the feasibility and benefits of the SOAR concept, experiments based on computer simulations are being developed to provide realistic assessment of the systems and scenarios. This paper reports on the progress of these experiments, following a brief overview of the SOAR concept in the next section.

\section{OVERVIEW OF SOAR CONCEPT}

Where a bottleneck exists for the traffic, tight control to achieve orderly traffic is the key to maximize flow efficiency through the bottleneck. The SOAR concept introduces advanced automation to the two main environments responsible for surface operation: the ground control environment and the flight deck. The SOAR automation technologies will deliver maximal performance when these two environments can be tightly integrated in a Centralized Decision-making, Distributed Control (CDDC) paradigm.

The surface traffic management (STM) automation system will provide the centralized decision-making functionality. It will base its decisions on surveillance data, flight plans and Airline Operational Control (AOC) requirements, to generate time-based taxi routes for optimum traffic efficiency. Advanced data-link will enable the issuance of complex taxi clearances for the flights to taxi according to the desired time-controlled taxi routes. An STM-automation concept, known as the
Ground-Operation Situation Awareness and Flow Efficiency (GO-SAFE) system [12], serves as the foundation for building the STM automation system envisioned by the SOAR concept. GO-SAFE provides the following functions to maximize surface traffic efficiency:

- Planning functions involving runway usage scheduling and conflict-free route planning to coordinate arrival, departure and taxiing traffics for maximum efficiency.

- Traffic control functions to facilitate issuance of clearances to flight deck for execution of the efficient taxi operations.

- $\quad$ Traffic monitor functions to ensure safety of traffic while executing the demanding operations.

- Graphic user interface (GUI) to support the aforementioned functions.

The flight-deck automation systems in the aircraft participating in the surface operation will collectively provide the distributed control of the overall traffic system in a collaborative manner. Advanced automation technologies will provide auto-taxi capabilities or automation aids to the pilots for performing precision taxi to achieve the time-controlled taxi routes issued as clearances by ground control. New operation procedures will need to be defined for carrying out data-linked clearances, and for automatic loading of the clearances into the aircraft's flight management systems (FMS). A previous effort has demonstrated with computer simulations that advanced nonlinear control methods can be deployed to control the aircraft's taxi operation to track very precisely defined time-constrained taxi routes, even in the highly dynamic environment of performing active-runway crossing immediately after the aircraft has landed on an adjacent runway [13]. The Flight-deck Automation for Reliable Ground Operation (FARGO) system represents further development of this idea to achieve the flight-deck automation component of the SOAR concept. FARGO provides the following functions to deliver the taxi performance required to achieve the surface traffic efficiency envisioned from GO-SAFE:

- Auto-taxi function to generate aircraft taxi control commands for achieving precision taxi requirements demanded by GO-SAFE-generated clearances.

- Pilot interface to enable pilots to execute precision taxi operations either in fully automatic mode or automation-assisted mode.

- Traffic monitor functions provided through pilot interface to alert pilots of deviation from cleared 
taxi routes or impending incursion by other vehicles.

Through this CDDC paradigm, the SOAR concept capitalizes on the integrated operation of the GO-SAFE and FARGO systems to enable ATC and the flight crew in achieving surface operations that balance the optimization of both airport capacity (in terms of maximizing arrival/departure efficiency) and surface traffic efficiency (in terms of minimizing taxi delay). The concept will also benefit from integrated operation with other advanced/automation systems through information exchange to maximize data accuracy. Information exchange with systems such as the SMS $[8,9]$, and Center/TRACON Automation System (CTAS) [14] with its various tools, including the Traffic Management Advisor (TMA) [15], Final Approach Spacing Tool (FAST) [16], Collaborative Arrival Planner (CAP) [17], and the Expedite Departure Path (EDP) tool [18], will enhance data accuracy that helps to minimize time buffers or separation requirements for operations. The time frame addressed by the SOAR concept is 2020 . Within this time frame, evolution of NAS is assumed to be consistent with the OEP, the FAA NAS Architecture [19], and the RTCA NAS concept document [20]. Figure 2 contains a highlevel block diagram of the SOAR concept.

\section{ANTICIPATED BENEFITS}

The SOAR concept enables airport capacity enhancement, especially that associated with airport expansion plans which produce complex airport configurations. For a given airport layout, the total traffic capacity is constrained by an upper bound that depends on two primary factors: the number of runways, and the maximum traffic rate per runway.
This upper bound can be considered to be the "ideal" capacity, which can be described as Pareto frontiers $[21,22,23]$ for the bi-objective problem of maximizing arrival rate and departure rate. (Pareto frontiers are basically the set of possible optimal solutions describing the tradeoff in a multi-objective optimization problem.) The maximum traffic rate per runway in turn depends on many factors, such as operational requirements on arrival/departure traffic mix, and aircraft separation due to wake vortex concerns.

In practice, the achievable capacity at the airport may be substantially lower than the ideal capacity due to inefficiency, much of which is caused directly or indirectly by interference among the traffic. The increase in airport configuration complexity resulting from the airport expansion exacerbates the inefficiency. A notable example is the increased number of activerunway crossings resulting from increased traffic and airport expansion. To bring the achievable capacity close to the ideal capacity, ATC operation can minimize the impact of active-runway crossings on takeoff and landing operations by minimizing the total time taken up by runway-crossing activities. This can be achieved by queuing up the flights that require crossing and clearing them to cross as a batch. The side effect is inevitably the increase in taxi delay when the flights have to line up and wait for a large enough group to form before crossing. Referring back to Figure 1, this represents a tradeoff between the two efficiency factors:

- Reduction in achievable traffic rate, a penalty on arrival/departure efficiency

- Increase in taxi delay, a penalty on surface traffic efficiency

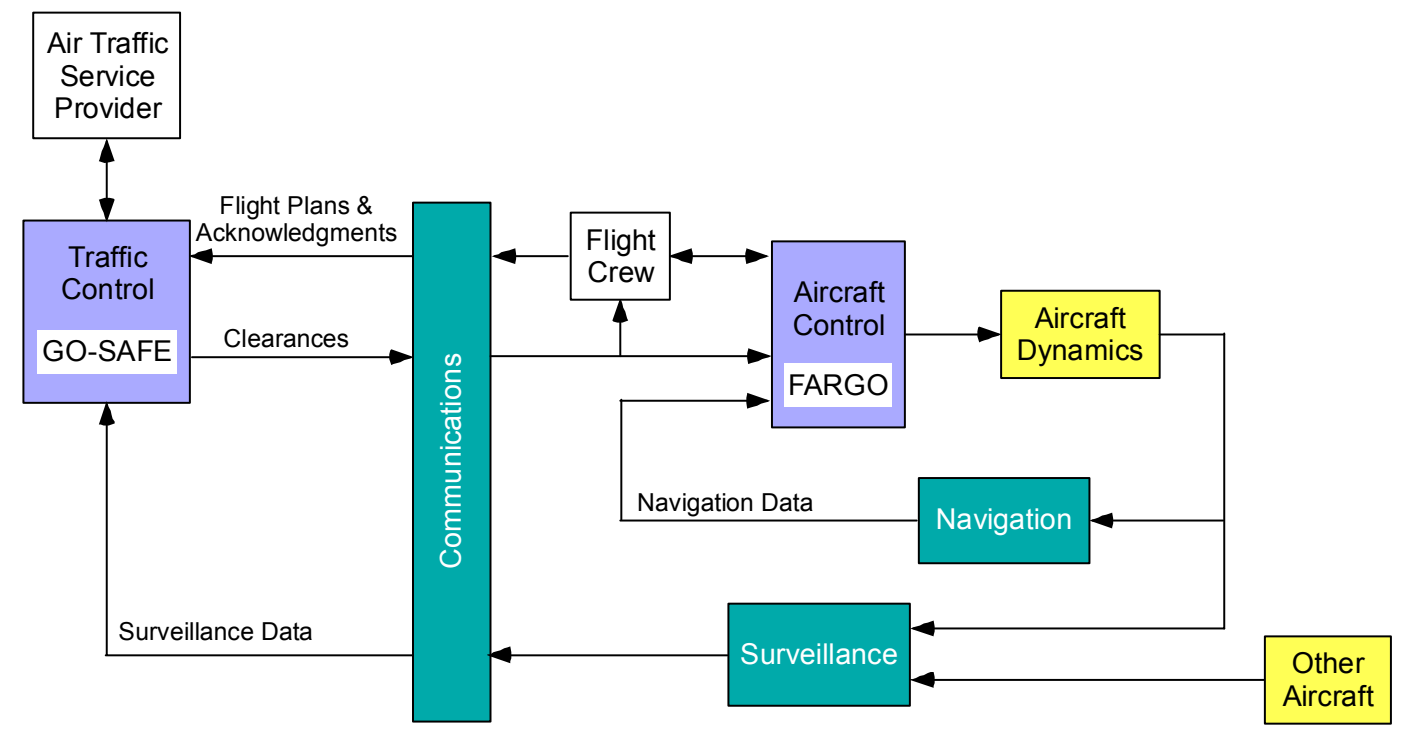

Figure 2. Top-Level Block Diagram of the SOAR Concept 
The anticipated benefits of the SOAR concept are tied to the reduction of these penalties:

1. Enabled by accurate surveillance, accurate landingtime predictions provide by other automation systems, and precision taxi performance enabled by FARGO, the GO-SAFE component of SOAR can plan and schedule landing, takeoff, and taxi operations to simultaneously enhance the arrival/departure efficiency and surface traffic efficiency. In other words, the SOAR concept can deliver close to peak traffic rates without introducing substantial taxi delay.

2. The GO-SAFE and FARGO user interfaces together with the underlying automation enable the human operators to deliver efficient operations otherwise unattainable with conventional user interfaces and operational procedures. In other words, they allow the operators to achieve higher performance within acceptable workload levels.

3. The user interfaces together with accurate surveillance data can potentially enhance safety by improving the situational awareness of the human operators to reduce confusion among flights, and by providing timely alert in case of impending conflicts.

All of these anticipated benefits will, of course, require extensive evaluation to substantiate specific claims.

\section{RELEVANT METRICS}

Benefits resulting from capacity-related concepts will largely consist of cost savings to current and future airport users associated with reduced time spent in the airport system [25]. Reduced time in system may take the form of reduced delay, more efficient processing, or reduced idle time. Capacity-related concepts may also contribute to the ability to process more operations and passengers, greater safety and security, reduced environmental impacts, greater comfort for travelers, and other benefits. With this in mind, the evaluation of a capacity-enhancement concept should not be looking at the allowable peak traffic rate alone, since this does not necessarily mean that the travel time for the airport users is minimized. To properly account for the benefits of a capacity-enhancement concept such as SOAR, the airport capacity in terms of arrival-departure throughput needs to be assessed together with surface traffic efficiency in terms of taxi delay.

The capacity improvement benefit can be quantified as the maximum number of flights that the airport can handle within a specific push period, or equivalently, the duration required for handling a push of a specific number of flights. These have to be evaluated under the assumption that enough gates are available. One way to gauge the capacity level is to compare it to maximum traffic throughput as dictated by required separation alone for the arrival and departure traffic, and ignoring any need for other uses of the runways such as active-runway crossing. The maximum throughput can be determined for a ratio between the arrival and departure traffics according to the Pareto frontiers. This is denoted as the "Ideal/Peak Capacity" in Figure 3. In practice, the effective capacity would be below the peak value. The objective of the SOAR concept is to increase the effective capacity in a manner that will not compromise safety.

The primary metric of surface traffic efficiency is taxi delay. To help calculate this quantity, baseline taxi time can be pre-determined for each taxi operation (e.g., from landing to the gate terminal, or from the gate terminal to departure). These baseline quantities should be established with nominal vehicle performance and without interference from other factors (e.g., this should not include any waiting for active-runway crossing). With these baseline taxi times, taxi delays can be calculated as the time difference required for taxi operation under the scenario traffic. Assuming one would not taxi faster than under nominal situations, the taxi delay is always non-negative:

$$
\begin{aligned}
\text { Taxi Delay } & =\text { Actual Taxi Time }- \text { Nominal Taxi Time } \\
& \geq 0
\end{aligned}
$$

Figure 3 suggests how the SOAR concept can improve on the capacity or the taxi delay [24].

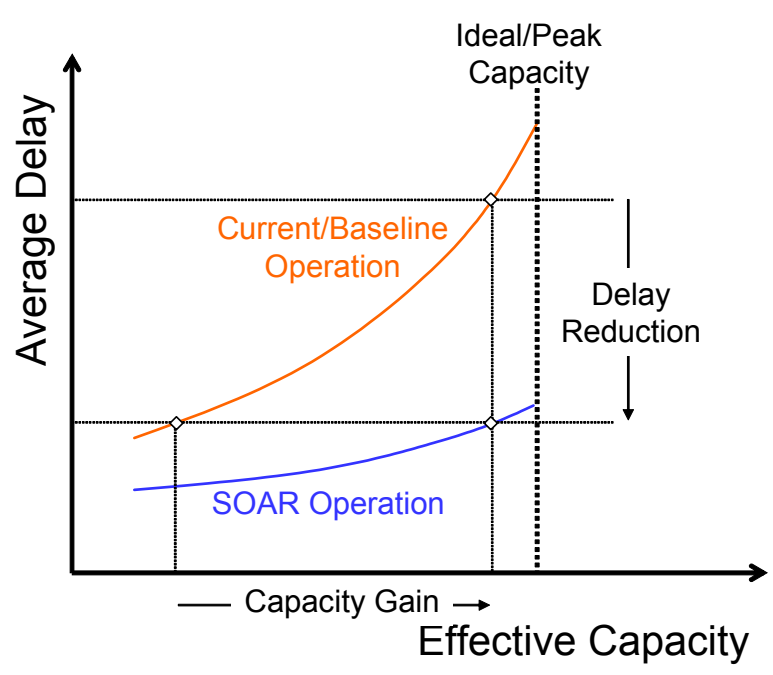

Figure 3. Anticipated SOAR Benefits of Capacity Gain and Delay Reduction 
One can also use the taxi time to define an individualvehicle taxi efficiency:

$$
\begin{aligned}
\text { Taxi Efficiency } & =\frac{\text { Nominal Taxi Time }}{\text { Actual Taxi Time }} \\
& =\frac{\text { Actual Effective Speed }}{\text { Nominal Effective Speed }} \leq 1
\end{aligned}
$$

which can be generalized to a surface traffic efficiency metric:

$$
\text { Surface Traffic Efficiency }=\frac{\sum \text { Nominal Taxi Time }}{\sum \text { Actual Taxi Time }} \leq 1
$$

With this metric, the improvement in the tradeoff between airport capacity and surface traffic efficiency can be illustrated by the relationship suggested in Figure 4.

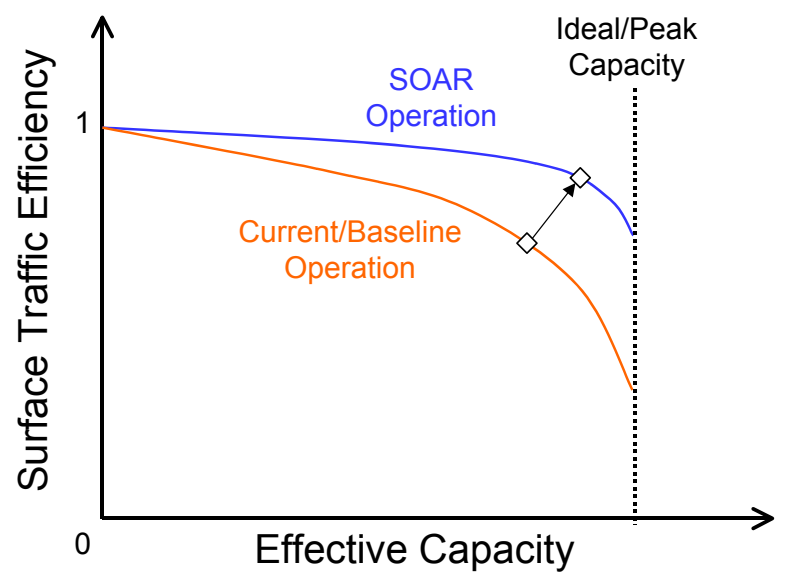

Figure 4. Enhanced Tradeoff Between Surface Traffic Efficiency and Airport Capacity

The improvement of taxi efficiencies of individual aircraft can also be viewed as histograms as suggested by Figure 5, as long as the data from the different operational modes have been generated to produce the same effective capacity.

Enhancement in surface traffic efficiency also has secondary effects on controller workload. These workload factors can be assessed through various techniques such as questionnaires and workload rating systems when performing human-in-the-loop evaluations. In computer simulations, it may be possible to model required human activities to perform their operational functions, and use post-simulation data analyses to assess whether the required activities are within reasonable limits.

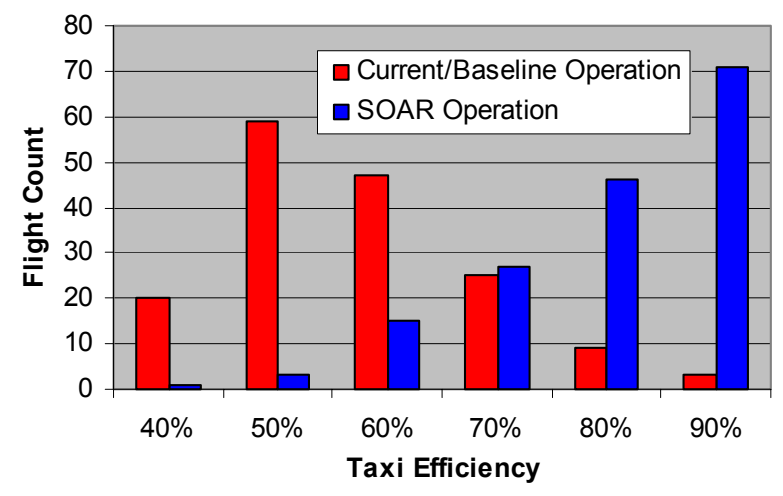

\section{Figure 5. Comparison of Histograms of Taxi Efficiency for Different Operational Modes with Same Effective Capacity}

The primary measure of safety is separation violation, including runway incursions. With human-in-the-loop simulations, natural uncertainties of human-pilot control and implementations of the various systems, including the SOAR systems, will help identify whether the advanced SOAR technologies and enabling technologies can effectively maintain safety under tight operational requirements. With computer simulations, uncertainties would have to be introduced into the simulations to represent human and system inaccuracies. In addition, stochastic analyses can be performed using Monte-Carlo techniques or other statistical techniques such as covariance analysis.

\section{Evaluation Plans}

Development and evaluation of the SOAR concept is currently being supported by the NASA Virtual Airspace Modeling and Simulation (VAMS) program. The program plan includes several evaluation activities in the next few years. An evaluation of the concept is planned for 2003 by Optimal Synthesis Inc. (OSI), the concept originator, using computer simulations. This is described as the Surface Domain Evaluation in Figure 6. This evaluation will be based on an experimental implementation of GO-SAFE and a computer simulation of the surface traffic. It will assess the capacity/efficiency tradeoff, and compare the results with those obtained from a model representing current operations without the benefit of the automation systems.

Planned for 2004 is an evaluation to be performed at NASA Ames Research Center using the Airspace Concept Evaluation System (ACES) [26] to assess the NAS-wide impact of the SOAR concept. This activity is described as the Low-Fidelity NAS-Wide Assessment in Figure 6. If possible, an intermediate experiment - Terminal Traffic Impact Assessment - 


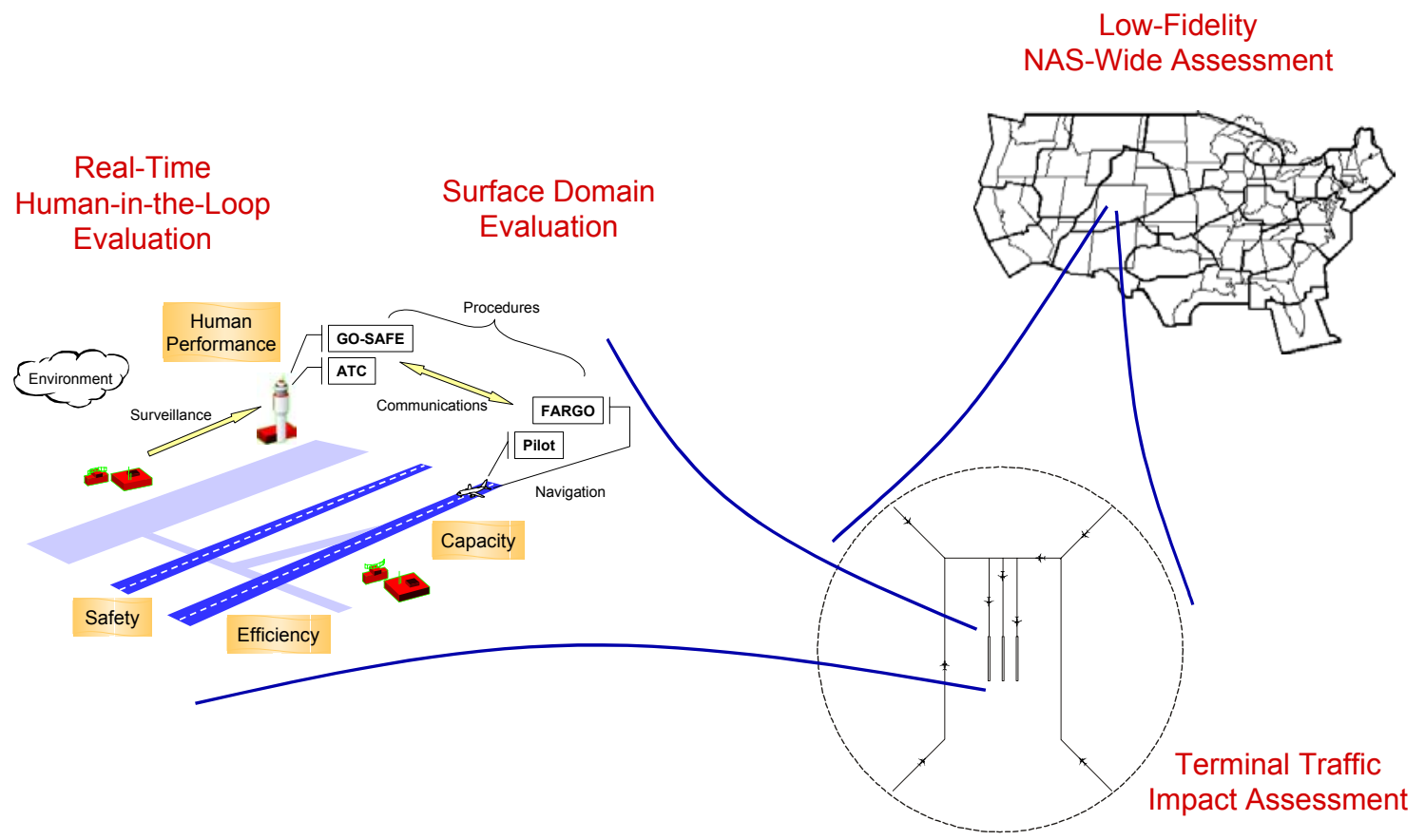

Figure 6. Evaluation Options for SOAR Concept

will be performed to capture the impact of the SOAR concept on the TRACON traffic for propagating the effects to the NAS-wide model.

It is hoped that after the 2004 experiments, resources will be available to perform a Real-Time Human-inthe-Loop Evaluation. This type of experiments will involve human subjects in realistic cockpit simulators as well as control tower simulators. The experiments will be useful for assessing roles and responsibilities of operators and automation systems, human performance and workload, effectiveness of user interfaces, operational procedures, including those required for handling unexpected events.

\section{EXPERIMENT DESIGNS}

The surface domain evaluation of the SOAR concept will be performed through computer simulations. To properly evaluate SOAR, we need to account for the differences between the SOAR concept and current operations, which serve as the baseline. These differences are reflected by SOAR's automation as compared to current manual operations that include human delay and comparatively large uncertainties of expected performances. Specifically, simulation of the baseline operations should include:

- Human delays in issuing, acknowledging, and executing clearances

- Aircraft control uncertainty due to manual control
- Aircraft holding at runways while waiting for clearance to cross

- Hand-off of flights between local and ground controllers

- Human ATC situation awareness involving visual activities out the tower windows

The effects of these activities will be compared to those achievable with SOAR automation.

Development of the computer simulations will build upon the surface-traffic simulation available at OSI. Figure 7 illustrates how the existing setup of the simulation is being modified to evaluate the SOAR concept. The existing setup has three software components: GO-SAFE, its GUI, and the GroundOperation Simulation (GO-Sim). These are separate processes that can run on different computers communicating over the network. The aircraft dynamics in GO-Sim incorporate a nonholonomic rolling constraint to realistically model an aircraft being steered with its nose gear.

The first modification being introduced is to include separate simulation of human operator activities for the controllers and flight crews with the SOAR automation systems. An application program interface (API) is introduced to mimic the controller activities with the GO-SAFE GUI. Once the simulation software for this scenario is obtained, it will be modified further for simulation of the current operations, where the SOAR 


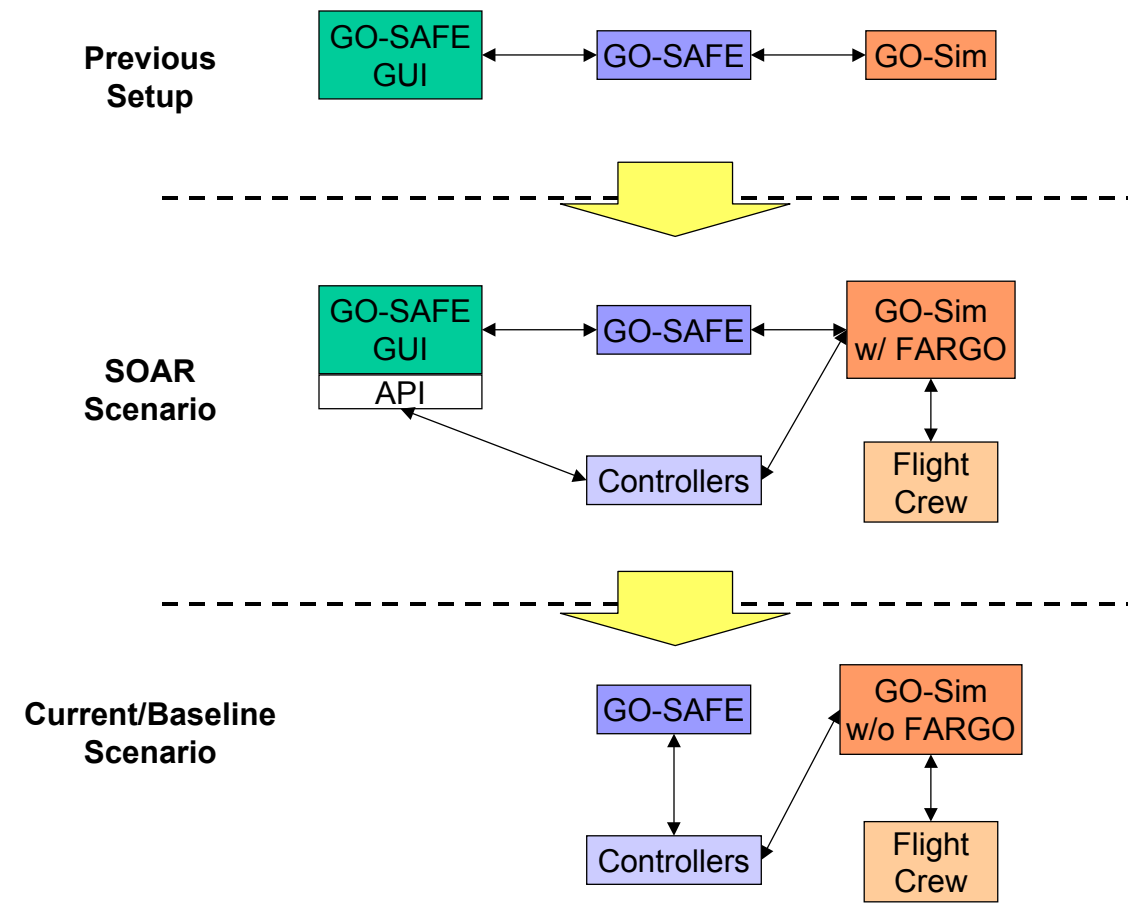

Figure 7. Modification of Surface-Operation Simulation for SOAR Self-Evaluation

automation will be removed, and the human activities will be adjusted to reflect the manual operations. Additional uncertainties will be introduced in the GOSim and flight crew components to represent operation without FARGO automation.

In the current effort on the design and implementation of the simulations, one major activity involves integration of the planning functions in GO-SAFE. Specifically, the software modules of GO-SAFE in route planning, runway usage scheduling, and conflict resolution are being combined to produce a simultaneous route-planning function for multiple flights. This modification will enhance GO-SAFE performance, and it also represents a more realistic simulation of the human decision-making process when the planning functions are converted to simulate the controller operation in the baseline scenario.

Another activity is the definition of the human operator activities for both the baseline scenario corresponding to current operations and the SOAR scenario with advanced automation. Table 1 through Table 4 contain examples of roles and responsibilities of the ground controllers and the flight crews with lists of associated activities. Specifically, Table 1 and Table 2 contain the information for the departure ground control under the current operations and SOAR operations, respectively; and Table 3 and Table 4 contain similar information for the flight crews. Similar lists are prepared for other human operators such as the local controllers, and for the automation systems. The activities identified in these lists are to be encoded in the computer simulations to study their effects on the performance of the SOAR concept.

Every attempt will be taken to ensure that the evaluations are performed in an objective, unbiased manner. Evaluation scenarios will be based on actual NAS data to represent current operations as well as data scaled up to represent future requirements. For instance, Official Airline Guide (OAG) data can be used to create traffic scenarios for defining current requirements.

\section{CONCLUDING REMARKS}

Limitation in airport runway throughput naturally constrains traffic capacity. For this reason, attempts to increase capacity ultimately will require airport expansion to increase the number of runways and associated taxiways. Often the airport expansion plans cause an unavoidable increase in the complexity of surface traffic, affecting adversely the surface traffic efficiency, and ultimately holding back some of the potential benefits. The Surface Operation Automation Research (SOAR) project produces a concept that explores the use of collaborative automation systems to enhance surface operation performance in a complex airport environment.

The SOAR effort being supported by the NASA Virtual Airspace Modeling and Simulation (VAMS) project involves studying the feasibility and benefits of the 
SOAR concept. The effort involves computer simulations for the surface domain to study the benefits and limitations of the concept, and well as low-fidelity simulations to study the impact of the concept on NASwide traffic. This paper represents an interim report on the current effort to design and implement the computer simulations.

To adequately address the performance enhancements made possible by the SOAR automation, the simulations need to capture the sources of taxioperation inefficiencies and the ability of the SOAR automation to alleviate them. To this end, the roles and responsibilities of the human operators and the automation systems need to be modeled in the simulations.

Evaluation analyses will be performed after the simulations are implemented, and the results are expected to be presented in future articles.

\section{ACKNOWLEDGMENT}

Study of the SOAR concept is currently being supported by the NASA VAMS (Virtual Airspace Modeling and Simulation) project under Contract No. NAS2-02073. The development of the experimental GO-SAFE system was supported in part by NASA under Contract No. NAS2-99055. The study on aircraft precision taxi was supported in part by NASA under Contract No. NAS2-98057.

\section{REFERENCES}

[1] National Airspace System Operational Evolution Plan, Version 5.0, Federal Aviation Administration, December 2002.

[2] Capezzuto, V., D. Olster, M. Curry, and S. L. Pendergast, "Runway Incursion Reduction Program (RIRP) Surveillance System, NASA/FAA Atlanta Demonstration," Proceedings of the IEEE/AIAA $17^{\text {th }}$ Digital Avionics Systems Conference, Bellevue, WA, Oct. 31-Nov. 7, 1998, Paper F31.

[3] Castaldo, R., "Positive Identification of Aircraft on Surface Movement Areas - Results of FAA Trials," Air Traffic Control Technologies II, Orlando, FL, April 10-11, 1996, SPIE Proceedings Vol. 2737, pp. 134-142.

[4] Evers, C., R. Cassel, and D. Lee, "Analysis of ADS-B, ASDE-3 and Multilaterlation Surveillance Performance - NASA Atlanta Demonstration," Proceedings of the IEEE/AIAA $17^{\text {th }}$ Digital Avionics Systems Conference, Bellevue, WA, Oct. 31-Nov. 7, 1998, Paper F33.
[5] Edwards, V., and C. Evers, "Loop Technology (LOT) as an Alternative Surface Surveillance System," Proceedings of the IEEE/AIAA $17^{\text {th }}$ Digital Avionics Systems Conference, Bellevue, WA, Oct. 31-Nov. 7, 1998, Paper F45.

[6] Hicok, D. S., and D. Lee, "Application of ADS-B for Airport Surface Surveillance Proceedings of the IEEE/AIAA $17^{\text {th }}$ Digital Avionics Systems Conference, Bellevue, WA, Oct. 31-Nov. 7, 1998, Paper F34.

[7] Glass, B. J., "Automated Data Exchange and Fusion for Airport Surface Traffic Management," AIAA Guidance, Navigation, and Control Conference, New Orleans, LA, Aug. 11-13, 1997, Paper AIAA-97-3679.

[8] Brinton, C., J. Krozel, B. Capozzi, and S. Atkins, "Improved Taxi Prediction Algorithms for the Surface Management System," Proceedings of the AIAA Guidance, Navigation, and Control Conference, Monterey, CA, August 5-8, 2002, Paper AIAA 2002-4857.

[9] Atkins, S., C. Brinton, and D. Walton, "Functionalities, Displays, and Concept of Use for the Surface Management System," Proceedings of the $21^{\text {st }}$ Digital Avionics Systems Conference, Irvine, CA, October 27-31, 2002, Paper 1.D.6.

[10] Cheng, V. H. L., "Collaborative Automation Systems for Enhancing Airport Surface Traffic Efficiency and Safety," Proceedings of the 21st IEEE/AIAA Digital Avionics Systems Conference, Irvine, CA, October 29-31, 2002.

[11] Cheng, V. H. L., "Airport Surface Operation Collaborative Automation Concept," Proceedings of the AIAA Guidance, Navigation, and Control Conference, Austin, TX, August 11-14, 2003.

[12] Cheng, V. H. L., and D. C. Foyle, "Automation Tools for Enhancing Ground-Operation Situation Awareness and Flow Efficiency," Proceedings of the AIAA Guidance, Navigation, and Control Conference, Monterey, CA, August 5-8, 2002.

[13] Cheng, V. H. L., V. Sharma, and D. C. Foyle, "Study of Aircraft Taxi Performance for Enhancing Airport Surface Traffic Control," IEEE Transactions on Intelligent Transportation Systems, Vol. 2, No. 2, June 2001.

[14] Erzberger, H., T. J. Davis, and S. Green, "Design of Center-TRACON Automation System," Proceedings of the 56th AGARD Symposium on Machine Intelligence in Air Traffic Management, Berlin, Germany, 1993, pp. 11-1-11-12. 
[15] Swenson, H. N., T. Hoang, S. Engelland, D. Vincent, T. Sanders, B. Sanford, and K. Heere, "Design and Operational Evaluation of the Traffic Management Advisor at the Fort Worth Air Route Traffic Control Center," 1st USA/Europe Air Traffic Management $R \& D$ Seminar, Saclay, France, June 1997.

[16] Davis, T. J., K. J. Krzeczowski, and C. Bergh, "The Final Approach Spacing Tool," Proceedings of the 13th IFAC Symposium on Automatic Control in Aerospace, Palo Alto, CA, September 1994.

[17] Quinn, C., and R. E. Zelenka, "ATC / Air Carrier Collaborative Arrival Planning," $2^{\text {nd }}$ USA/Europe Air Traffic Management R\&D Seminar, Orlando, FL, December 1-4, 1998.

[18] Jung, Y. C., and D. R. Isaacson, "Design Concept and Development Plan of the Expedite Departure Path (EDP)," Proceedings of the AIAA Aircraft Technology, Integration, and Operations (ATIO) Conference, Los Angeles, CA, October 1-3, 2002.

[19] National Airspace System Architecture Version 4.0, Federal Aviation Administration, January 1999.

[20] Government and Industry Guidelines and Concepts: NAS Analysis and Redesign, Prepared by SC-192, RTCA, December 14, 2000.

[21] Idris, H. R., B. Delcaire, I. Anagnostakis, W. D. Hall, J. P. Clarke, R. J. Hansman, E. Feron, and A. R. Odoni, "Observations of Departure Processes at Logan Airport to Support the Development of Departure Planning Tools," 2nd USA/Europe Air Traffic Management R\&D Seminar, Orlando, FL, December 1-4, 1998.

[22] Lee, D. A., C. Nelson, and G. Shapiro, "The Aviation System Analysis Capability Airport Capacity and Delay Models," NASA Contractor Report, NASA/CR-1998-207659, Prepared for Langley Research Center under Contract No. NAS2-14361, April 1998.

[23] Long, D., D. Lee, E. Gaier, J. Johnson, and P. Kostiuk, "A Method for Forecasting Commercial Air Traffic Schedule in the Future," NASA Contractor Report, NASA/CR-1999208987, Prepared for Langley Research Center under Contract No. NAS2-14361, January 1999.

[24] “OEP Metric Plans,” Industry Coordination Draft, Version 1.1, September 30, 2002.

[25] "FAA Airport Benefit-Cost Analysis Guidance," Office of Aviation Policy and Plans, Federal Aviation Administration, December 15, 1999.
[26] Sweet, D. N., V. Manikonda, J. S. Aronson, K. Roth, and M. Blake, "Fast-Time Simulation System for Analysis of Advanced Air Transportation Concepts," Proceedings of the AIAA Modeling and Simulation Technologies Conference, Monterey, CA, August 5-8, 2002, Paper No. AIAA 2002-4593. 
Table 1. Sample List of Ground-Controller Activities under Current Operations

\begin{tabular}{|c|c|c|}
\hline Roles & Responsibilities & Activities \\
\hline \multirow[t]{5}{*}{$\begin{array}{l}\text { Ground Controller - } \\
\text { Departure }\end{array}$} & Situation Awareness & $\begin{array}{l}\text { - Monitor traffic out the tower windows. } \\
\text { - } \quad \text { Monitor traffic on ASDE display. } \\
\text { - Monitor radio communication. }\end{array}$ \\
\hline & Planning & $\begin{array}{l}\text { - } \text { At DFW: radio ramp spots sequentially to get flight } \\
\text { ID; at other airport, respond to radio contact by flights. } \\
\text { - } \quad \text { Determine departure runways for flights. } \\
\text { - } \quad \text { Determine taxi routes for flights. } \\
\text { - } \quad \text { Coordinate with local controllers for runway crossings. }\end{array}$ \\
\hline & Clearance Issuance & $\begin{array}{l}\text { - Issue clearances for taxi, hold, etc. } \\
\text { - Wait for clearance acknowledgments. }\end{array}$ \\
\hline & Hand-off & - Clear flight to contact tower controller for departure. \\
\hline & $\begin{array}{l}\text { Response to Unplanned } \\
\text { Events }\end{array}$ & $\begin{array}{l}\text { - Monitor out-the-window traffic, ASDE display, and } \\
\text { radio communications for unplanned events. } \\
\text { - } \quad \text { Retermine vehicles affected by events. } \\
\text { - React to ensure safety. } \\
\text { Replan in response to unplanned events. }\end{array}$ \\
\hline
\end{tabular}

Table 2. Sample List of Ground-Controller Activities under SOAR Operations

\begin{tabular}{|c|c|c|}
\hline Roles & Responsibilities & Activities \\
\hline \multirow[t]{5}{*}{$\begin{array}{l}\text { Ground Controller - } \\
\text { Departure }\end{array}$} & Situation Awareness & 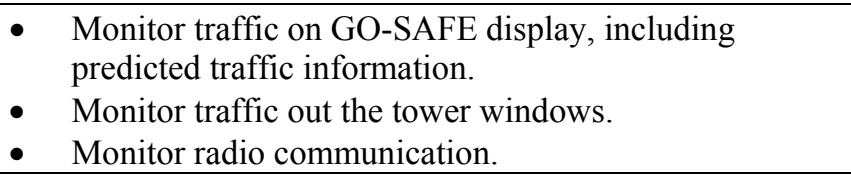 \\
\hline & Planning & $\begin{array}{l}\text { - Monitor GO-SAFE advisories. } \\
\text { - } \quad \text { Coodify advisories as desired. } \\
\text { through advisory modifications/execution or directly. }\end{array}$ \\
\hline & Clearance Issuance & $\begin{array}{l}\text { Issue pre-clearances with complete taxi routes and } \\
\text { departure information via data link. } \\
\text { - } \quad \text { Monitor status regarding acceptance of pre-clearances. } \\
\text { - } \text { Issue clearances for taxi, broken into segments if } \\
\text { necessary, and wait for quick acknowledgments. } \\
\text { Monitor status of clearances and need to issue } \\
\text { subsequent clearances for successive segments. }\end{array}$ \\
\hline & Hand-off & $\begin{array}{l}\text { Hand-off of flight to tower controller via data link is } \\
\text { performed through GO-SAFE. } \\
\text { Designation of new radio frequency for voice } \\
\text { communication can be either through direct voice } \\
\text { instruction, or message via data link. This step may be } \\
\text { avoided if the new procedures under SOAR require no } \\
\text { change in frequency. }\end{array}$ \\
\hline & $\begin{array}{l}\text { Response to Unplanned } \\
\text { Events }\end{array}$ & $\begin{array}{l}\text { - Monitor GO-SAFE for unplanned events and indication } \\
\text { of affected vehicles. } \\
\text { - React to ensure safety. } \\
\text { Replan in response to unplanned events with GO-SAFE } \\
\text { planning functions. }\end{array}$ \\
\hline
\end{tabular}


Table 3. Sample List of Flight-Crew Activities under Current Operations

\begin{tabular}{|c|c|c|}
\hline Roles & Responsibilities & Activities \\
\hline \multirow[t]{5}{*}{ Pilot - Captain } & Situation Awareness & $\begin{array}{ll}\text { - } & \text { Monitor traffic outside cockpit window. } \\
\text { - } & \text { Monitor CDTI. }\end{array}$ \\
\hline & Clearance Handling & $\begin{array}{l}\text { - Communicate with co-pilot and authorize co-pilot to } \\
\text { accept or reject clearance. }\end{array}$ \\
\hline & Planning & $\begin{array}{l}\text { - Develop mental picture of taxi operation based on } \\
\text { clearance. }\end{array}$ \\
\hline & Aircraft Control & - Manually control aircraft to execute taxi operation. \\
\hline & $\begin{array}{l}\text { Response to Unplanned } \\
\text { Events }\end{array}$ & $\begin{array}{l}\text { - React to avoid catastrophe. } \\
\text { - When safe to do so: continue previously cleared } \\
\text { operation if possible; otherwise request new clearance. }\end{array}$ \\
\hline \multirow[t]{3}{*}{ Co-Pilot - First Officer } & Clearance Handling & $\begin{array}{l}\text { Obtain clearances from controllers, and take note of } \\
\text { key data. } \\
\text { - Confirm with pilot the content and acceptability of the } \\
\text { clearances. } \\
\text { - Acknowledge clearances. }\end{array}$ \\
\hline & Aircraft Control & $\begin{array}{l}\text { - Assist pilot in controlling aircraft by performing } \\
\text { assigned tasks. }\end{array}$ \\
\hline & Hand-off & $\begin{array}{l}\text { - Switch radio frequencies and communicate with } \\
\text { different controllers. }\end{array}$ \\
\hline
\end{tabular}

Table 4. Sample List of Flight-Crew Activities under SOAR Operations

\begin{tabular}{|c|c|c|}
\hline Roles & Responsibilities & Activities \\
\hline \multirow[t]{5}{*}{ Pilot - Captain } & Situation Awareness & $\begin{array}{l}\text { - } \quad \text { Monitor traffic outside cockpit window } \\
\text { - } \quad \text { Monitor FARGO display. }\end{array}$ \\
\hline & Clearance Handling & $\begin{array}{l}\text { Understand pre-clearances and communicate with co- } \\
\text { pilot regarding acceptance. } \\
\text { - Authorize co-pilot to acknowledge clearances. }\end{array}$ \\
\hline & Planning & $\begin{array}{l}\text { - Use FARGO display to understand required operations } \\
\text { based on clearance. } \\
\text { - Understand limits of clearances in effect to ensure } \\
\text { additional segments are cleared to facilitate } \\
\text { uninterrupted operation. }\end{array}$ \\
\hline & Aircraft Control & $\begin{array}{l}\text { - Use FARGO display and, where appropriate, auto-taxi } \\
\text { capability to execute control. }\end{array}$ \\
\hline & $\begin{array}{l}\text { Response to Unplanned } \\
\text { Events }\end{array}$ & $\begin{array}{l}\text { - React to avoid catastrophe. } \\
\text { - When safe to do so: continue previously cleared } \\
\text { operation if possible; otherwise request new clearance. }\end{array}$ \\
\hline \multirow[t]{3}{*}{ Co-Pilot - First Officer } & Clearance Handling & $\begin{array}{l}\text { - Interpret pre-clearances and confirm with pilot } \\
\text { regarding acceptance. } \\
\text { - Acknowledge clearances. } \\
\text { - } \text { Download clearances into FARGO system. }\end{array}$ \\
\hline & Aircraft Control & $\begin{array}{l}\text { - Assist pilot in controlling aircraft by performing } \\
\text { assigned tasks. }\end{array}$ \\
\hline & Hand-off & $\begin{array}{l}\text { - Switch radio frequencies and communicate with } \\
\text { different controllers as necessary. }\end{array}$ \\
\hline
\end{tabular}

